\title{
Learning Materials Representation for Interoperability in Heterogeneous Environment
}

\author{
Mostafa Saleh \\ Faculty of Computing \& Information Technology \\ King Abdulaziz University, Jeddah 21589, Saudi Arabia \\ msherbini@kau.edu.sa
}

\begin{abstract}
.
Learning resources are used for different learners and in different contexts along with heterogeneous environments. So, we need a way to enable automatic selection and compilation of these learning resources and adapt them to the target learner within these heterogeneous environments. This paper proposes using semantic web technologies and specially ontology in adaptive modeling of the learning resources to select the suitable material to the right learner in heterogeneous environment. We have implemented the ontology using Protégé 5.5.0. This proposed ontology model can help instructors and resource designers.
\end{abstract}

Key words: Learning Resources, Learning Objects, Ontology, Metadata, Interoperability, Reusability, Heterogeneous Environment, Content Ontology, Educational Ontology.

\section{INTRODUCTION}

Recent years have witnessed an increased interest in educational organizations and institutions to support anyone, anywhere, anyhow, and anytime learning. But this explosive growth of these systems and their generated learning materials have has led to difficulty in locating the most relevant learning resources to match the goals, needs, and preferences of their learners. There is some level of granularities in these learning resources as they may be courses, chapters, lectures, or the smallest unit of learning called learning object (LO).From the abstraction point of view, we can consider all of these granularity levels as learning objects but they are ranging from coarse to fine grained levels of granularities as shown in Figure 1.The curriculum represents the main coarse grained level, as it represents the whole study guide for the program. The second level is the course to represent or to support certain objective of the curriculum. Then, there is a chapter, and finally the learning object, which represents the fine grained granularity level.Each of course, chapter, and learning object has learning resource ontology to describe. Generally, the learning object or learning resource is defined in the literature as "a type of digital content component that allows flexibility, independence, and reuse of content in order to deliver a high degree of control to instructors and students" [1].

E-learning systems have generated huge number of LOs that make the location of suitable ones a big challenge.Traditional e-Learning systems are based on "one-size-fits-all" or "one-to-many" approach where the same learning materials are presented to all learners with the same style, time, and manner.

Adapted e-Learning systems are those learning systems tailored to the learners' preferences and needs so it is "one-to-one" approach. Therefore, personalized learning system needs to adapt automatically to the learner's preferences and intelligently present the appropriate learning activities that lead to improving the learning process.

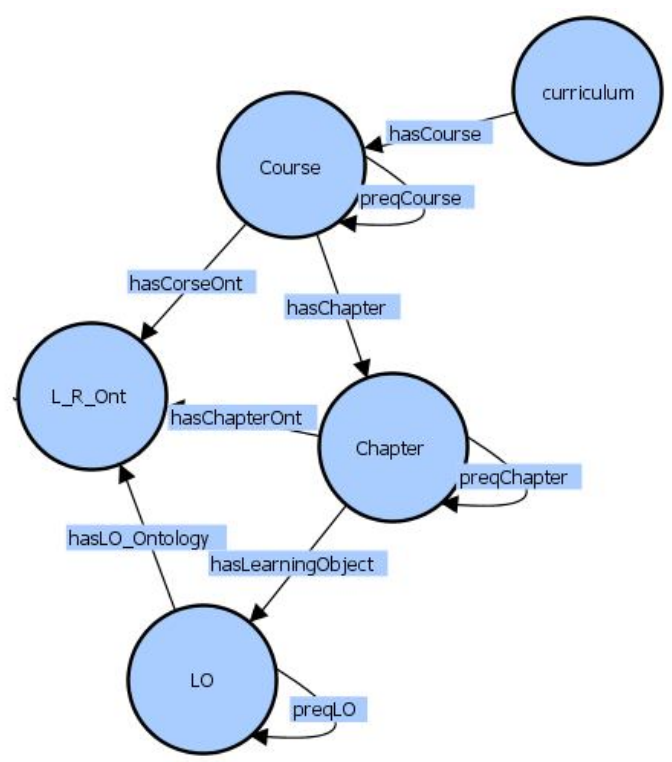

Figure 1:. Learning Contents Granularities

Resources recommendation is to recommend the suitable learning resources to learners. We can find two types of recommendation systems: collaborative filtering recommendation; and content-based recommendation. Collaborative filtering recommendations[2-5] are used within adaptive e-learning to give learners recommendations about courses and give teachers and instructors some teaching instructions [6]. But collaborative filtering systems don't give attention to the nature of contents within the recommended objects, so, 
any type of learning objects (learning resources) can be recommended by the recommendation algorithm.

The second kind is to recommendbased on content. Recommendations were always based on semantic similarity [7]. Researchers analyze the contents of the available learning resources and try to match them with the given keywords or to match them with learning historical data of the learners based on similarity between them.

Because of these disadvantages, some researchers have tried to use semantic web technologies within resource recommendation process to get better learning experiences [8]. Semantic web aims to give better communication between machines and between people and machines [9]. So, machine can have better understanding of the meaning (semantic) and relationships between different resources within the knowledge. This feature makes it possible to automatically recommend resources based on semantics [8]. Therefore, integrating the learning diagnosis and pedagogics in e-learning recommendation system based on semantics has achieved little notice.

So, augmentingontology within the recommendation process can solve the problems and limitations of the normal recommender systems. Ontology-based or (knowledge-based)recommendation systems are using ontologyto representknowledge about concepts (items)and their relationships along with taxonomy of these concepts, and knowledge about users of the recommender system. In e-learning, for example, ontology-based recommendation systems use ontology to represent the knowledge about the learning resources and learners, and try to support the learner with the relevant learning resources. So, ontology plays a significant role in knowledge: representation, reuse, and share in these systems [10]. To enable ontology-based recommendation, learning materials need to be annotated using ontology.

Web technologies give a great support and gained good share in the ongoing success of e-learning community by supporting reusability of learning resources, designing learning modules, and digital repositories availability [11]. Unfortunately, in the current web (Web 2.0), everything within it is based on syntax, and is readable but not understandable by machines[12]. So, e-learning solutions are less flexible and less interoperable. So, we need to supportlearning contents to be context aware using semantic web and ontology.

So, we need to annotate the learning resources using different types of ontologies to enable the machine to understand and easy process these resources. Then machines can match them with learner model to retrieve the most suitable resources based on the learner's profile. Consequently, adapted systems can deliver effective and efficient learning to the learners.

Another important issue gained by using ontology is the semantic interoperability between software systems. To gain this semantic interoperability,systems need to model their data using ontologies. Also, they need to represent these resources using the same data representation format to be understandable for both applications. For example, using RDF, and OWL [13].

The size and scope of the learning resources (learning contents) that we can combine to a bigger content package is a key point to consider. For instance, we can combine only a few coarse grained pieces of learning contents to fulfill certain learning objective. But, repackaging them to form a new package that fulfill another similar learning objective but in different context may not be possible [14].

To enable good reusability, learning resources should be fine grained to the lowest achievable level (small units such as LOs). Using smaller fine-grained learning units, course authorshave better flexibility to use them to create additional content packages in different contexts. For instance, if learning resources are available at a fine grained level such as the paragraph, then the course author can easily add or remove contents at this low level and produce custom-made courses [14].

Recently, researches have directed their effort towards contents reusability. For instance, Brooks and McCalla[15] analyzed the relation between LOs and Semantic Web. They explored the importance of ontologies in e-learning systems, and their interoperability, but did not give much details about the ontology and its categories and attributes.

Gaševiü et al. [16] suggested to use ontology to enhance LOs content. They suggested to create LOs annotated with domain ontology. Then, these LOs can be used as learning materials in e-learning, and also, they can be used and utilized in other realworld applications.

Ostreika et al. [17] proposed LO design model based on ontology and presents the importance of using ontology during the LOs creation process. They explored the role of ontologies, and semantic web in offering intelligent elearning systems. But they did not give much more details about the LOs creation process.

Vanjulavalli [18] explored that learners need much more materials and spend much more time to learn about a particular subject. So, they need much more reusability and interoperability of the learning resources. He has developed "C programming" ontology. But he did not talk about the other ontologies used in preparing the learning resources.

Gudoniene et al. [19] presented the role of semantic web in the design, exchange, and storage of LOs, to enable the search and share of these LOs. They reviewed LO Standards and Metadata by comparing IEEE LOM, Can Core LOM, and Dublin Core metadata.

Koutsomitropoulos, and Solomou [20] proposed an enhancement for educational metadata within IEEE LOM and introduced a repository for learning object ontology to help in publishing, discovering, and reusing LOs.

Wang, and Wang [21] surveyed the semantic technology and ontology used within e-learning systems during the last decade. They examined the use of ontology in these systems by reviewing the different aspects such as the level of richness in these educational ontologies. 
Sein-Echaluce et al. [22] developed a framework based on the Web 3.0 (ACCI 3.0), where all the resources prepared by teachers and students are based on ontology. So, these resources can be transferred to other subjects. Their proposed ACCI 3.0 framework was constructed by augmenting their ACCI 2.0 system with a semantic layer. They aim to give the teacher the role of facilitator and give the student the role of resources creator.

This paper presents an ontological model to annotate the learning resources, so, human and machine can find, reuse, and integrate them in heterogeneous environments. This is achieved by building ontologies for LO: domain (curriculum); contextual; educational; and structural knowledge. These ontologies are represented using OWL (Web Ontology Language). OWL is a widely accepted standard proposed by the World Wide Web Consortium (W3C) for representing ontology.

The organization of the rest of this paper is as follows. Section 2 discusses the learning contents ontology. Section 3 is directed to discuss content domain (curriculum) ontology. Section 4 is directed to present the educational ontology, where section 5 is devoted to context ontology. Section 6 is devoted to discuss content structure ontology. Finally, section 7 is directed to the conclusion.

\section{LEARNING CONTENTS ONTOLOGY}

Ontology is used formally to describe shared meaning between used concepts by making relationships between these concepts. Also, ontology puts set of constrains on these relationships. In e-learning, ontology is needed on several levels of contents preparation,which are related to several aspects of document usage, as shown in Figure 2. This enables the reusability of these learning resources and support the interoperability between different and heterogeneous systems.

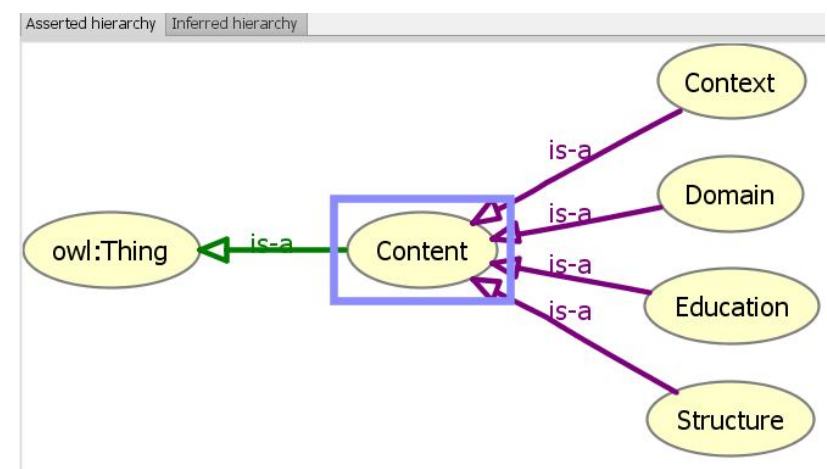

Figure 2: Learning ContentsOntology.

Metadata is data about data, i.e. using data to define data such as name, tel., address [20]. We need to use metadata with a common format to describe LOs. Consequently, this description enables LOs to be read and understood by machines. Dublin Core (DC) Schema is a common metadata schemes for general purpose description and released by Dublin Core Metadata
Initiative Group [23]. DC has a set of 15 attributes. For example, these attributes include: Title, Identifier, Contributor, Creator, Format, Publisher, Relation, rights, and Comment. Qualified Dublin Core uses some additional attributes to support further refinement of resources meaning. The DCMI recommended some qualifiers to enhance the description of different elements. For example, the "Title" element, has "Name, Definition, Label, or Comment" qualifiers [23].

Dublin Core aims to give metadata to describe any kind of digital resources. So, it did not support the special specification required to describe learning resources. The"Learning Objects Metadata" (LOM) [24] introduced by the "Learning Technology Standards Committee" (LTSC) from IEEE made extension to DC to enable learning resources description. So, LOM is used as the basic and the initial metadata model for the learning community. Other communities established other standards based on LOM. For instance, "Instructional Management System" (IMS) [25], and SCORM [26], [27]are based on IMS.

To enable global search for learning objects (resources), we have suggested a Global Learning Object Identifier (GLOID). This GLOID enables uniqueness of learning object's ID. For example, we can find the same course title within Computer Science, Computer Engineering, and Information systems. We can differentiate between them by curriculum defining each program. Figure 3 shows a sample for GUID for the Computer Science field.

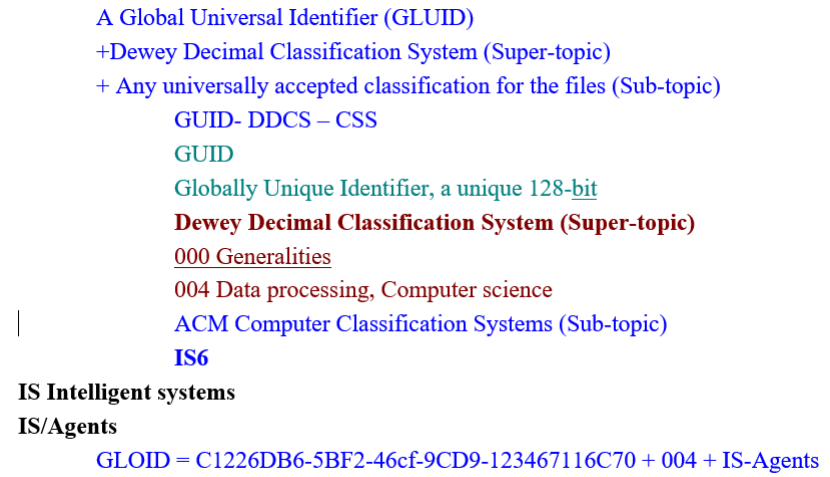

Figure 3: A Sample GLOID for CS Field.

The reusability at this level is only for the whole LO. So, to enable the content author to reuse part of the LO, we need to give much more descriptions about the LO. This can be achieved by using ontology to give much more details about the LO contents, context, and structure. Next sections discuss domain (curriculum) ontology; educational ontology;context ontology; and structure ontology to support more reusability levels.

Content's domain ontology is used to describe what the learning material is about, educational ontology represents the educational characteristic of the LO, context ontology is used to describe the form of presenting the LO, and structure ontology is used to 
describe in which style the learning material will appear to the user. The proposed solution assumes inheriting the description of the learning resource to its components.

The rationale behind using different ontologies is to enable software agents to semantically search learning resources repositories. So, they can search for a resource of type "introduction", dealing with a certain topic "Semantic Web" and being at a certain level of granularity such as "slide". This also enables content authors to combine more learning resources to have a new resource with certain objectives.

\section{CONTENT DOMAIN (CURRICULUM) ONTOLOGY}

In order to enable effective learning object contents reusability, we have to further enhance their semantic. Content's domain ontology is used to describe what the learning material is about. A learning resource created using this principle can give much more reusability as it can be embedded in different courses and with different learning strategies. For example, in the ACM Curricula [28], the "AL3. Fundamental computing algorithms" knowledge units include"Simple numerical algorithms; sequential and binary search algorithms; quadratic and $\mathrm{O}(\mathrm{N} \log \mathrm{N})$ sorting algorithms; hashing; and binary search trees"which are taught as topics within (CS111. Introduction to Programming, CS112. Data Abstraction, and CS210. Algorithm Design and Analysis). Also, teaching a course such as "Introduction to Computer" to Literature students will be different in form, style and depth from those students in other disciplines such as Medicine, Science and Engineering.

One important question arises here, as there is domain ontology within the learning object metadata, why it is recommended to use domain ontology to describe the learning object contents itself? The answer is simple, as the domain ontology for the learning object as a whole describes the learning object as a concrete unit and can't give details about the contents. Also, no restrictions are put on learning resource granularity, so, learning resources developers can prepare their material by including many variations for the same learning object in the same package. For example, the developer can package the whole information about a whole lecture in one learning object unit.

According to ACM Computer Science Curricula 2013 [28], the Body of Knowledge (BoK) of ACM/IEEE has a set of Knowledge Areas (KAs) related to typical areas of study in computing such as Complexity, Algorithms, and Operating Systems. Each KA is divided down into Knowledge Units (KUs). Each KU has a set of topics.

To determine the requirements to design a course about any of CS courses, there are many knowledge areas, under these knowledge areas we can find description about the requirements for each course.For example, to find a course about "Database Systems" we can navigate to (IM-Information Management) category and under that category, there is "Database Systems". Also, to find a course about "Agents" we can navigate to IS category (IS Intelligent Systems) and under that IS category we can find "IS- Agents" as shown in Figure 4.
The shared-understanding for the same concept in the domain is very important in e-learning systems. This enables resource(s) creator to define the right contents to the right audience, and also, supports locating the right resources from repositories. In e-learning, two people can express the same topic in two different ways. So, they can define identical concepts (i.e. topics in elearning content) using different keywords. For example, to express the "Agent" concept, one may use the following semantically equivalent terms "agent, actor, contributor, creator, player, worker, and performer". The problem could be solved using domain ontologies where we can map pings from user vocabularies into the commonly-agreed-upon terms in the domain ontology. This research suggested using concepts in Table 1 to enrich the domain ontology description. The namespace "locVoc" is used to denote the learning object content vocabularies. Figure 5 gives RDF code to describe the similar concepts to the "Agent" concept within the domain ontology.

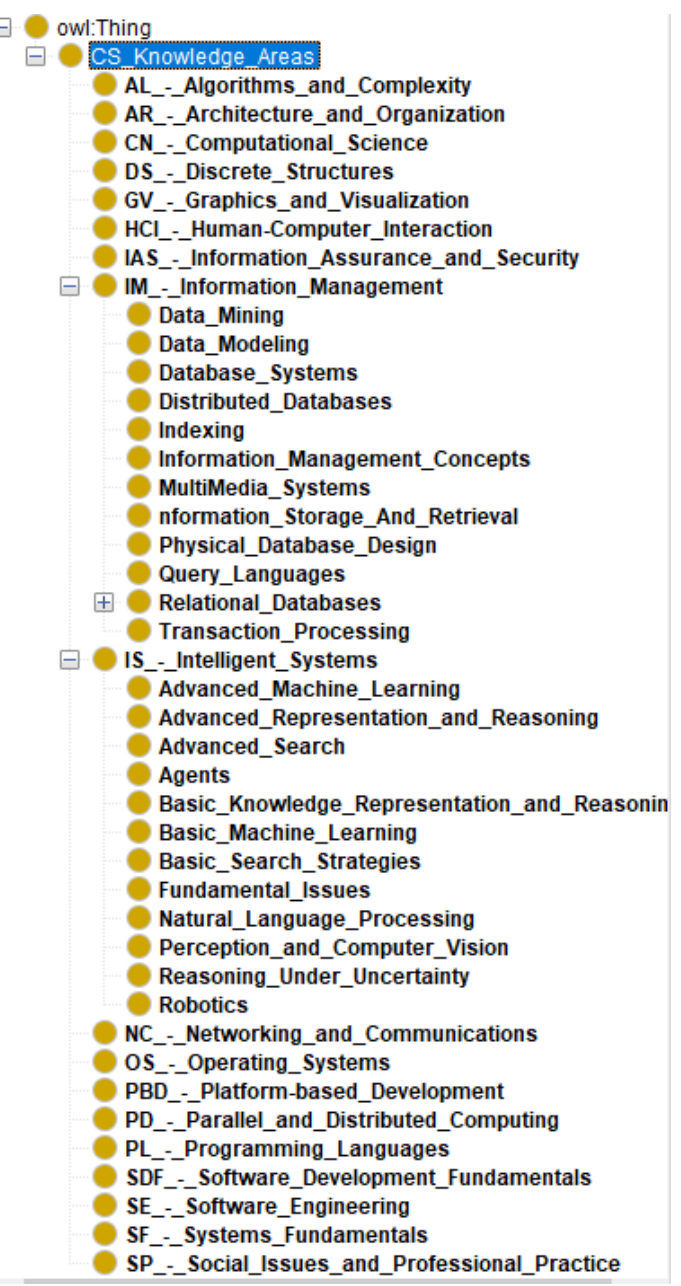

Figure 4: Domain Ontology for Computer Science, and the details of "Intelligent Systems" 
Table 1: Added Ontological Metadata Items to the Domain Ontology.

\begin{tabular}{|l|l|}
\hline Metadata element & Description \\
\hline locVoc:Keyword & $\begin{array}{l}\text { A related synonyms keyword } \\
\text { for searching. }\end{array}$ \\
\hline locVoc:App-Field & $\begin{array}{l}\text { The field of application for } \\
\text { that domain. }\end{array}$ \\
\hline $\begin{array}{l}\text { locVoc:CourseOnt- } \\
\text { TYPE }\end{array}$ & $\begin{array}{l}\text { Course ontology within the } \\
\text { sub topic classification } \\
\text { identifier. }\end{array}$ \\
\hline $\begin{array}{l}\text { locVoc: CourseOnt- } \\
\text { VAL }\end{array}$ & $\begin{array}{l}\text { The value assigned to that } \\
\text { content according to the } \\
\text { chosen course ontology. }\end{array}$ \\
\hline
\end{tabular}

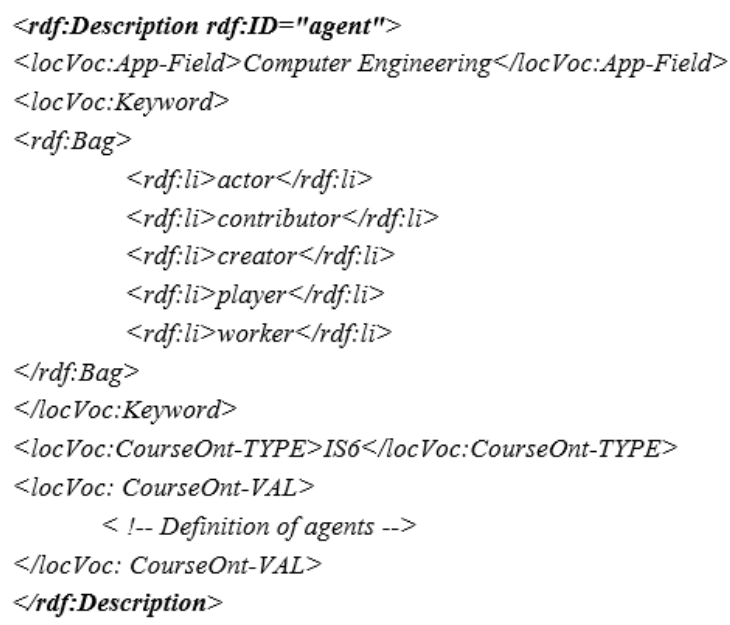

Figure 5: Added Domain Ontology Concepts about "Agent".

The majority of the domain ontology concepts can be inherited from the whole learning object metadata, so, the items used in the learning object content metadata are minimized and directed to those items related to synonyms keywords, and field of application. For example, for teaching statistics to Medicine students, we should choose the application fieldof study to be Medicine to be easy understood as possible as we can.

\section{EDUCATIONAL ONTOLOGY}

Educational ontology represents the educational features for the learning resources. These features include for example:LearningResourceType, InteractivityType, InteractivityLevel, and InstructionalRole. So, these features can help in recommending the right learning material to the right learner based on his profile. Table 2 presents the added ontological items to the educational ontology. We started with the educational category from IEEE LOM [24] and added some complementing properties. The namespace "lom-edu" is used to denote the educational category of IEEE LOM, whereas "edu" is used to denote the suggested properties.
Table 2: Added Ontological Items toEducational Ontology.

\begin{tabular}{|c|c|c|}
\hline Educational Item & Description & Samples \\
\hline $\begin{array}{l}\text { lom- } \\
\text { edu:InteractivityT } \\
\text { ype }\end{array}$ & $\begin{array}{l}\text { The interactivity type } \\
\text { supported by the } \\
\text { learning resource }\end{array}$ & $\begin{array}{l}\text { active, expositive, } \\
\text { mixed, undefined }\end{array}$ \\
\hline $\begin{array}{l}\text { lom- } \\
\text { edu:LearningReso } \\
\text { urceType }\end{array}$ & $\begin{array}{l}\text { The type of the } \\
\text { presented resource }\end{array}$ & $\begin{array}{l}\text { figure, exercise, table, } \\
\text { simulation, graph, } \\
\text { diagram, index, slide, } \\
\text { experiment, lecture, } \\
\text { exam }\end{array}$ \\
\hline $\begin{array}{l}\text { lom- } \\
\text { edu:InteractivityL } \\
\text { evel }\end{array}$ & $\begin{array}{l}\text { Interactivity degree of } \\
\text { the learning resource }\end{array}$ & $\begin{array}{ll}\text { very low, low, } \\
\text { medium, high, very } \\
\text { high }\end{array}$ \\
\hline $\begin{array}{l}\text { lom- } \\
\text { edu:SemanticDen } \\
\text { sity }\end{array}$ & $\begin{array}{l}\text { Degree of conciseness } \\
\text { of a learning resource }\end{array}$ & $\begin{array}{lll}\text { very low, low, } & \text { lodium, high, } & \text { very } \\
\text { medigh } & & \end{array}$ \\
\hline $\begin{array}{l}\text { lom- } \\
\text { edu:Difficulty }\end{array}$ & $\begin{array}{l}\text { Difficulty level of the } \\
\text { learning resource. }\end{array}$ & $\begin{array}{l}\text { very easy, easy, } \\
\text { medium, difficult, very } \\
\text { difficult }\end{array}$ \\
\hline $\begin{array}{l}\text { edu:InstructionalR } \\
\text { ole }\end{array}$ & $\begin{array}{l}\text { The instructional role } \\
\text { that can be achieved } \\
\text { by the learning } \\
\text { resource. }\end{array}$ & $\begin{array}{l}\text { introduction, } \\
\text { definition, overview, } \\
\text { example, fact, } \\
\text { illustration, } \\
\text { comparison, } \\
\text { explanation, summary, } \\
\text { theory, role, formula, } \\
\text { procedure, algorithm, } \\
\text { exercise, case study, } \\
\text { real world problem, } \\
\text { recall, question, } \\
\text { question Answer, case } \\
\text { study }\end{array}$ \\
\hline edu:ContentType & $\begin{array}{l}\text { They type of the } \\
\text { content }\end{array}$ & abstract, concrete \\
\hline $\begin{array}{l}\text { lom- } \\
\text { edu:typicalLearni } \\
\text { ngTime }\end{array}$ & $\begin{array}{l}\text { The average learning } \\
\text { time }\end{array}$ & $\begin{array}{l}5,10,15,20 \text { minutes } \\
\text { etc. }\end{array}$ \\
\hline $\begin{array}{l}\text { edu:learningGoal } \\
\text { Cognitive }\end{array}$ & $\begin{array}{l}\text { The learning goals of } \\
\text { the cognitive domain. }\end{array}$ & $\begin{array}{l}\text { knowledge, } \\
\text { comprehension, } \\
\text { application, analysis, } \\
\text { synthesis, evaluation }\end{array}$ \\
\hline $\begin{array}{l}\text { edu:learningGoal } \\
\text { Attitude }\end{array}$ & $\begin{array}{l}\text { The learning goals of } \\
\text { the attitude domain. }\end{array}$ & $\begin{array}{l}\text { receiving, responding, } \\
\text { valuing, organizing, } \\
\text { characterizing by value }\end{array}$ \\
\hline $\begin{array}{l}\text { edu:learningGoal } \\
\text { Skill }\end{array}$ & $\begin{array}{l}\text { The learning goals of } \\
\text { the skill domain. }\end{array}$ & $\begin{array}{l}\text { imitation, } \\
\text { manipulation, } \\
\text { precision, articulation, } \\
\text { naturalization }\end{array}$ \\
\hline
\end{tabular}

Both the "Technical Format" and the "Instructional Role" properties are important for the adaptation process based on learner model. For example, the "Technical Format" is used to select the learning resource based on learner learning style, and the "Instructional Role" can help the sequencing of the learning resources according to the learning style.

\section{CONTEXT ONTOLOGY}

Learning materials may be presented to learners in various contexts such as: introduction, explanation, analysis, discussion, conclusionetc. Also these learning materials could be presented in different presentation contexts such as: text, audio, video, or figure. Moreover, they can be presented in different user contexts such as: learner, instructor, or developer.So, giving context description to the learning resources 
facilitates the searching process based on the user's preferences.

For example, if the user needs to retrieve quick information about the topic he already knows, he can retrieve a summary of the topic. On the other hand, to get moredetailed information about the topic, he can retrieve the full version of the learning resource. Also, for mastering the prerequisite concept, learner may need to see the full version of the required prerequisite resource or he may be satisfied by reviewing the recall version of it. These suggested context information is presented in Table 3. The namespace "lom-edu" is used to denote the educational category of IEEE LOM, whereas "con" is used to denote the suggested context properties.

Table 3: Added Ontological Items in Context Ontology.

\begin{tabular}{|l|l|l|}
\hline Context Item & Description & Sample \\
\hline lom-edu:Context & $\begin{array}{l}\text { The environment } \\
\text { intended for running } \\
\text { the learning resource }\end{array}$ & $\begin{array}{l}\text { school, university, } \\
\text { training }\end{array}$ \\
\hline con:lern-Context & The learning context. & $\begin{array}{l}\text { introduction, } \\
\text { explanation, } \\
\text { analysis, } \\
\text { discussion, } \\
\text { conclusion }\end{array}$ \\
\hline con:pres-Context & $\begin{array}{l}\text { The type of media } \\
\text { presented }\end{array}$ & $\begin{array}{l}\text { text, audio, video, } \\
\text { or figure }\end{array}$ \\
\hline $\begin{array}{l}\text { lom- } \\
\text { edu:IntendedEnd } \\
\text { UserRole }\end{array}$ & $\begin{array}{l}\text { Intended viewer of the } \\
\text { learning resource }\end{array}$ & $\begin{array}{l}\text { learner, instructor, } \\
\text { or } \\
\text { manager }\end{array}$ \\
\hline con:type & $\begin{array}{l}\text { The learning resource } \\
\text { presentation type: full } \\
\text { presentation or recall } \\
\text { (brief). }\end{array}$ & full, recall \\
\hline con:Keyword & $\begin{array}{l}\text { Synonyms keywords } \\
\text { for searching. }\end{array}$ & \\
\hline
\end{tabular}

For instance, in a course presented in Computer Science about "Agents", the concept "Definition of agents" can have different presentation contexts: instructor context where a brief definition is presented; and student context where detailed information based on student's preferences with detailed definition and animation are presented.

Also, the same user may need the information in different presentation contexts. For instance, to solve mathematical equations, learner may need only the basic steps of solving the equation, or he may need animations to show the solution, or he may prefer interactive presentation while solving the equation.

\section{CONTENT STRUCTURE ONTOLOGY}

Learning contents are normally complex in structure. So, they need great care and patience to develop. Much of these contents will not be presented continuously as they depend on the learner preferences. Also, the structure of these material is not static as it also depends on the learner's type, knowledge level, preferences and on the prerequisite materials. To describe the structure of a learning module, we need to define the relations between the small constituting units of that module. For example, if that module is a course, we need to define the structure of the smaller units such as lectures to constitute that course based on learner's requirements.

There are several kinds of relations (properties) to structure the relationships between the basic learning resources. For example, next, prev, prequesit, isPrequiest, hasPart, isPartOf, isReferencedBy, hasReference, hasBase, isBaseFor, required, and isRequired.

Table 4. presents the added ontological relationships in the structure ontology. The namespace "dcterms" is used to denote the Dublin Core terms, whereas "str" is used to denote the suggested structural relationships.

Also, there may be a reverse semantic relationship between some of these relations. For example, hasPart andisPartOf are mutually inverserelations. So, defining that a relationship is the inverse of the other can help in the searching process. For example, if one defined a learning resource called "A" "isPartOf" some other learning resource called "B", without programming, he can't deduce that learning resource "B" has "hasPart" called "A". But by specifying the inverse relationship between them, the reasoner can deduce that that learning resource "B" has "hasPart" called "A" easily.

Table 4: Added OntologicalRelationships in the StructureOntology.

\begin{tabular}{|l|l|l|}
\hline Object Property & Inverse Concept & Comment \\
\hline structure & & $\begin{array}{l}\text { The structural } \\
\text { ontology section }\end{array}$ \\
\hline dcterms:prev & dcterms:next & $\begin{array}{l}\text { The sequence of } \\
\text { presentation. }\end{array}$ \\
\hline dcterms:isPartOf & dcterms:hasPart & $\begin{array}{l}\text { The super/sub } \\
\text { class relation. }\end{array}$ \\
\hline $\begin{array}{l}\text { dcterms:reference } \\
\text { s }\end{array}$ & $\begin{array}{l}\text { dcterms:isReferenced } \\
\text { By }\end{array}$ & $\begin{array}{l}\text { The link between } \\
\text { contents. }\end{array}$ \\
\hline $\begin{array}{l}\text { dcterms:isBasedO } \\
\text { n }\end{array}$ & dcterms:isBasisFor & $\begin{array}{l}\text { The prerequisite } \\
\text { relation. }\end{array}$ \\
\hline $\begin{array}{l}\text { str:isComplement } \\
\text { edBy }\end{array}$ & str:complementedOf & \\
\hline str:isversionof & str:hasversion & \\
\hline str:isformatof & str:hasformat & \\
\hline str:references & str:isreferencesby & \\
\hline str:isbasedon & str:isbasisfor & $\begin{array}{l}\text { Concept } \\
\text { similarities }\end{array}$ \\
\hline str:requires & str:isRequiredby & \\
\hline $\begin{array}{l}\text { str:isSameAs, } \\
\text { str:isSimilarTo,str } \\
\text { :isRelatedTo }\end{array}$ & & \\
\hline
\end{tabular}

Also, the following instructional relationships can be used to relate learning objects to each other: isIntroductionOf, isFactOf, isLawOf, idDefinitionOf, isProcessOf, isExampleOf, isCounterExampleOf, isExperimentOf, isProofOf, isExerciseOf, isRemarkOf, isConclusionOf, isTestOf, isExtensionOf, and isDeepOf.

According to ACM [28], the course in "Agents" can be presented as in Figure 6. Figure 7 represents the "Software Agent" module in Protégé GUI, whereas Figure 8 represents the OWL code for the structure of a learning object about "Agent architectures" with respect to the course "Agents" and also with respect to 
other modules, and other lectures. This is a simple representation for the sake of simplicity, and clarity.

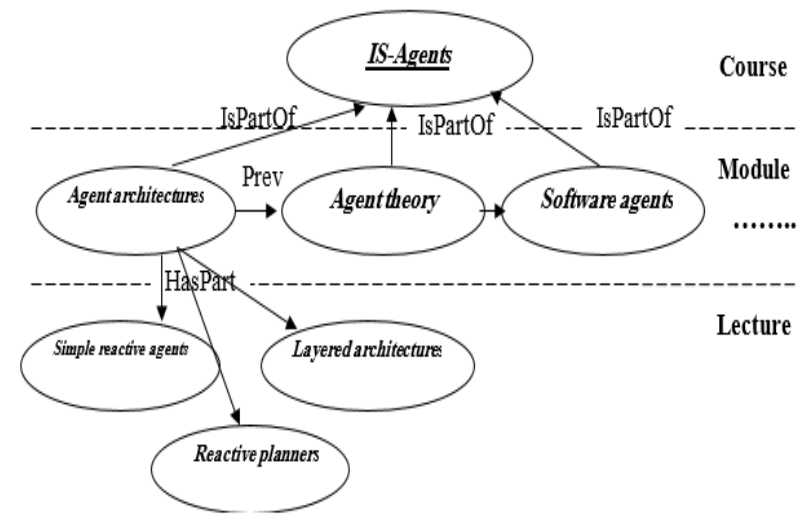

Figure 6: Part of Course Structure Ontology for "Agent".

Individuals: Software_agents
Agent_architectures
Agent_theory
IS-Agents
Layered_architectures
Reactive_planners
Simple_reactive_agents
Software_agents

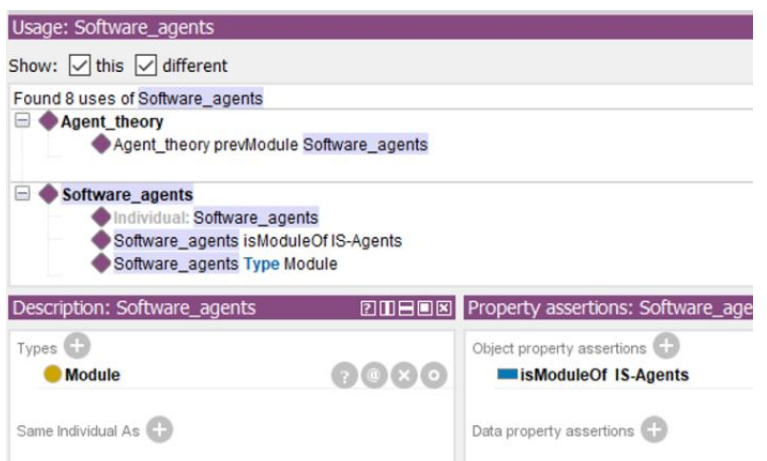

Figure 7: Representation of "Software Agents"

<owl:NamedIndividual rdf:about="

\#Agent_architectures">

<rdf:type rdf:resource=" \#Module"/>

$<$ hasLecture rdf:resource=" \#Layered_architectures"/>

$<$ hasLecture rdf:resource=" \#Reactive_planners"/>

$<$ hasLecture rdf:resource=" \#Simple_reactive_agents"/>

<isModuleOf rdf:resource=" \#IS-Agents"/>

$<$ prevModule rdf:resource=" \#Agent_theory"/>

$</$ owl:NamedIndividual $>$

Figure 8: OWL Code to Represent "Agent Architecture"

In this research, we have implemented the ontology using Protégé 5.5.0. Using ontology, we can make inference to extract new knowledge form the available knowledge. For example, using DL Query, we can ask about the modules that are subParts of some courses as shown in Figure 9.

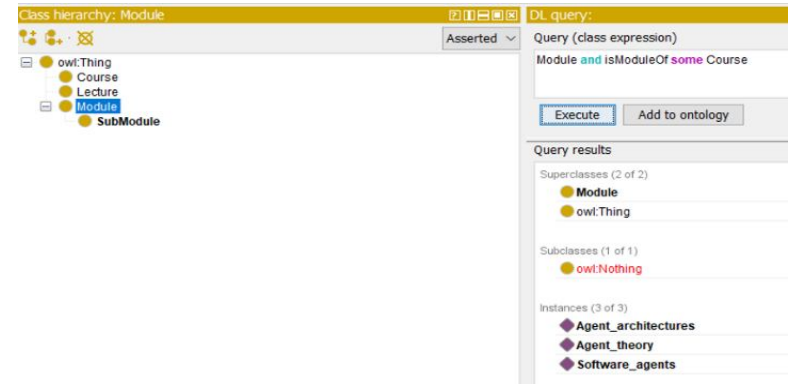

Figure 9: Using DL Query to Retrieve Course's Modules

Also, we have implemented the ontology for a "Web Programming" course using Protégé, and we can use reasoner to extract the implicit knowledge within ontology and converts it into explicit knowledge. For example, using reasoned, we can retrieve the implicit nextLectures for certain current lecture such as "Web Basics" as shown in Figure 10. All the shown nextLectures are implicitly mentioned, but as nextLecture is transitive, so the reasoner can retrieve all the nextLecture(s) in sequence.

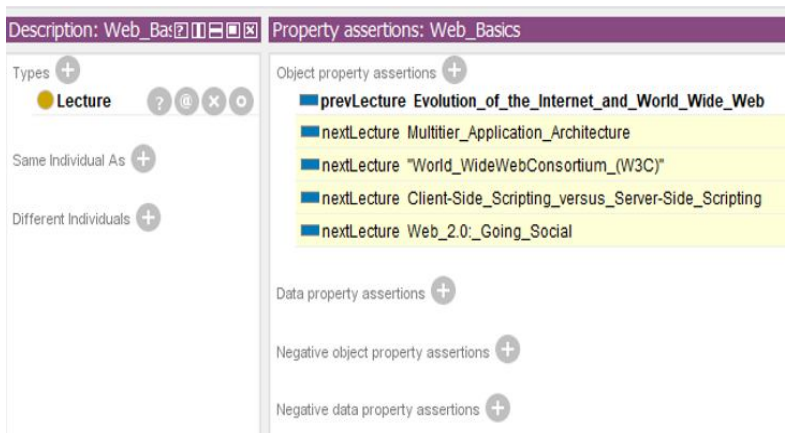

Figure 10: Retrieving the "nextLectures" for "Web Basics"

\section{CONCLUSION}

Adaptive e-Learning is a goal for many organizations. As they can adapt the learning material presented to the learner based on his preferences and characteristics. To prepare these learning material to support adaptability, and working in heterogeneous environment, authors need to spend much more time in preparing these learning resources. Also, authors spend much more time to design similar resources as they can't find a way to search and find the available resources.

This paper has presented an ontology-based approach to define these resources to enable finding, reusing them by human and machines. These ontologies include content's domain ontology to describe what the learning material is about, educational ontology to describe the educational features of these resources, context ontology is used to describe in which form the LO is presented, and structure ontology is used to describe in which style the learning material will appear to the user.

A prototype for the ontology has been implemented and tested by some cases of reasoning to find and extract the implicit knowledge and store it as explicit knowledge within the ontology itself. This work supports the workers in e-learning to assemble their learning objects from other learning object pieces and enables them to 
query learning resources according to domain, educational, context, and structure ontologies.

\section{REFERENCES}

[1] Bourkoukou, O., El Bachari, E., \& El Adnani, M. (2017). A recommender model in e-learning environment. Arabian Journal for Science and Engineering, 42(2), 607-617.

[2] Wu, L., Liu, Q., Zhou, W., Mao, G., Huang, J., \& Huang, H. (2018). A semantic web-based recommendation framework of educational resources in E-learning. Technology, Knowledge and Learning, $1-23$.

[3] Herlocker, J. L., Konstan, J. A., Terveen, L. G., \& Riedl, J. T. (2004). Evaluating collaborative filtering recommender systems. ACM Transactions on Information Systems (TOIS), 22(1), 5-53.

[4] Huang, Z., Zeng, D., \& Chen, H. (2007). A comparison of collaborative-filtering recommendation algorithms for e-commerce. IEEE Intelligent Systems, 22(5), 6878.

[5] Liu, C. L., \& Wu, X. W. (2016). Fast recommendation on latent collaborative relations. Knowledge-Based Systems, 109, 25-34.

[6] García, E., Romero, C., Ventura, S., \& De Castro, C. (2009). An architecture for making recommendations to courseware authors using association rule mining and collaborative filtering. User Modeling and UserAdapted Interaction, 19(1-2), 99-132.

[7] Meymandpour, R., \& Davis, J. G. (2016). A semantic similarity measure for linked data: An information content-based approach. Knowledge-Based Systems, 109, 276-293.

[8] Aroyo, L., \& Dicheva, D. (2004). The new challenges for e-learning: The educational semantic web. Journal of Educational Technology \& Society, 7(4), 59-69.

[9] Berners-Lee, T., Hendler, J., \& Lassila, O. (2001). The semantic web. Scientific American, 284(5), 28-37.

[10] Tarus, J. K., Niu, Z., \& Mustafa, G. (2018). Knowledge-based recommendation: a review of ontology-based recommender systems for elearning. Artificial intelligence review, 50(1), 21-48.

[11] David, P. (2007). A Design Requirements Framework for Distance Learning Environments. J Comput, 2(4), 99-113.

[12] West DM, Learning M (2013) Transforming Education, Engaging Students and Improving Outcomes. International Journal of ICT, EManagement and E-Learning 4

[13] Dobrev, P., Kalaydjiev, O., \& Angelova, G. (2007, July). From conceptual structures to semantic interoperability of content. In International Conference on Conceptual Structures (pp. 192-205). Springer, Berlin, Heidelberg.

[14] Dagger, D., Wade, V., \& Conlan, O. (2002). Towards a standards-based approach to e-learning personalization using reusable learning objects. In ELearn: World Conference on E-Learning in Corporate, Government, Healthcare, and Higher Education (pp.
210-217). Association for the Advancement of Computing in Education (AACE).

[15] Brooks, C., \& McCalla, G. (2006). Towards flexible learning object metadata. International Journal of Continuing Engineering Education and Life Long Learning, 16(1-2), 50-63.

[16] Gasevic, D., Jovanovic, J., \& Devedzic, V. (2004, August). Enhancing learning object content on the semantic web. In IEEE International Conference on Advanced Learning Technologies, 2004. Proceedings. (pp. 714-716). IEEE.

[17] Ostreika, A., Vasiu, R., Gudoniene, D., Maskeliunas, R., \& Rutkauskiene, D. (2015, October). An ontology oriented approach for e-learning objects design and improvement. In International Conference on Information and Software Technologies (pp. 138-150). Springer, Cham.

[18] Vanjulavalli, N. (2010, July). Ontology Based Conceptual Framework of E-Learning System-The Future Perspective. In International Conference on Data Engineering and Management (pp. 125-130). Springer, Berlin, Heidelberg.

[19] Gudoniene, D., Rutkauskiene, D., \& Dagiene, V. (2017, June). Search, Exchange and Design of Learning Objects in Learning Objects Repositories. In International Conference on Smart Education and Smart E-Learning (pp. 330-338). Springer, Cham.

[20] Koutsomitropoulos, D. A., \& Solomou, G. D. (2018). A learning object ontology repository to support annotation and discovery of educational resources using semantic thesauri. IFLA journal, 44(1), 4-22.

[21] Wang, Y., \& Wang, Y. (2019). A survey of semantic technology and ontology for e-learning. Semantic Web-Interoperability, Usability, Applicability. IOS Press Journal.

[22] Sein-Echaluce, M. L., Fidalgo-Blanco, Á., \& EstebanEscaño, J. (2019). Technological ecosystems and ontologies for an educational model based on Web 3.0. Universal Access in the Information Society, 18(3), 645-658.

[23] The Dublin Core Metadata Initiative http://dublincore.org/ (Last visited April 25, 2020)

[24] Learning Technology Standards Comittee of the IEEE: Draft Standard for Learning Objects Metadata IEEE P1484.12.1 http://ltsc.ieee.org/doc/wg12/LOM 1484 121 v1 Final Draft.pdf/

[25] IMS Digital Repositories Specification. http://www.imsglobal.org (Last visited April 25, 2020)

[26] ADL (2002). ADL SCORM Version 1.3 Application Profile. http://www.adlnet.orgLast visited April 25, 2020)

[27] Tmimi, M., Bouskine, K.,Khartoch, A., Benslimane, M., Ouazzani, K. (2020) A Proposed Conception of the domain Model forAdaptive Hypermedia, International Journal of Advanced Trends in Computer Science and Engineering, Advanced Trends in Computer, 9(3), $3261-3269$

[28] The ACM Computing Curricula (2013)

https://www.acm.org/binaries/content/assets/education/cs20 13_web_final.pdf

(Last visited April 25, 2020) 